\title{
Sea Water Aging of Glass Reinforced Composites: Shear Behaviour and Damage Modelling
}

\author{
P. DAVIES, ${ }^{1}$ F. MAZÉAS ${ }^{1}$ AND P. CASARI ${ }^{2}$ \\ ${ }^{1}$ Materials and Structures Group, IFREMER Centre de Brest, BP 70, \\ 29280 Plouzané, France \\ ${ }^{2}$ Laboratoire de Génie Civil de Nantes Saint Nazaire, \\ Faculté des Sciences et des Techniques de Nantes, \\ 2 rue de la Houssinière, BP 92208, 44322 Nantes cédex 03, France
}

\begin{abstract}
This paper presents results from a study of the wet aging of four thermoset resins and their $\left[0^{\circ} / 90^{\circ}\right]$ stitched glass fibre reinforced composites. The matrix resins are orthophthalic polyester, isophthalic polyester, vinyl ester and epoxy. Resins and composites were aged for 18 months, under three immersion conditions: $20^{\circ} \mathrm{C}$ sea water, $50^{\circ} \mathrm{C}$ sea water and $50^{\circ} \mathrm{C}$ distilled water. Tensile tests, on resins and at $45^{\circ}$ to fibre direction of composites, both before and after aging enable the influence of matrix resin and aging medium on weight changes and matrix dominated property degradation to be evaluated. This has enabled a unique dataset to be obtained. A large part of the shear property loss after aging is recovered after drying. An original application of damage mechanics parameters is used to quantify the changes in composite shear behaviour, in order to provide a more complete representation of the inelastic response.
\end{abstract}

KEY WORDS: marine, aging, immersion, sea water, thermoset, glass fibre, damage mechanics.

\section{INTRODUCTION}

ARINE STRUCTURES HAVE traditionally employed large amounts of polymer matrix composites, with applications ranging from pleasure boats to subma- 
rines [1-3]. The use of composites in a marine environment is increasing, both for naval construction and also for offshore and oceanographic purposes [4,5], and the applications are becoming more weight sensitive. This is leading to a need for optimized design and thinner structures, so that factors such as environmental degradation can no longer be neglected. Much work has been published on aging, particularly of high performance materials destined for the aerospace industry [6,7]. Such studies are of interest but not directly applicable to marine composites for several reasons.

First, the materials are rather different. The fibres used to reinforce marine composites are mainly E-glass. Carbon fibres have rarely been used outside racing yachts but their decreasing price will probably result in more applications in the future. Marine composites generally have lower fibre volume fractions (closer to $30 \%$ than $60 \%$ ), are produced by hand lay-up and impregnation rather than from prepreg, and are based on low temperature cure resins. The glass transition temperature of the matrix resin is therefore often below $80^{\circ} \mathrm{C}$, so that the possibilities of accelerating aging by increasing the temperature are limited.

The second difference between marine and aerospace composites is their working environment. For aerospace applications the most frequent environmental test involves exposure to $100 \%$ relative humidity and a temperature of $93^{\circ} \mathrm{C}$. The marine environments are sea water immersion and exposure to tidal splash zones or sea mist.

The designer of marine structures requires an appreciation of how different materials will respond to the marine environment over long periods of time. It is rarely possible to perform long tests at sea, so accelerated laboratory simulations are employed in conjunction with experience gained from previous designs. Distilled water is more readily available than sea water in test laboratories so in the majority of published studies the former is used as the aging medium. Few authors have directly compared the influence of sea water aging on the mechanical behaviour of composites with that of distilled water. Lagrange et al. compared diffusion kinetics for different glass reinforced polyester composites in the two media and noted an increase in water uptake for samples in distilled water but similar initial diffusion rates [8]. Grant also noted higher weight gains in vinyl ester composites after three months in distilled water when compared to the same period in artificial sea water [9].

Many of the reported aging studies involve elevated immersion temperatures (often $70^{\circ} \mathrm{C}$ or more) and quite short immersion periods (a few days or weeks). For example, Apicella et al. examined polyesters and their glass mat reinforced composites at 20 and $90^{\circ} \mathrm{C}$ for up to 50 days [10]. Little long duration aging data is available but an exception is a study by Gutiierrez et al., who present brief details of a correlation between $70^{\circ} \mathrm{C}$ laboratory aging and 30 year natural aging results [11]. Choqueuse et al. presented more detailed results from a 2 year distilled water aging study at four temperatures $\left(5,20,40\right.$ and $\left.60^{\circ} \mathrm{C}\right)$ [12]. Weitsman summarized 
wet aging studies of composites recently [13] and concluded that although current predictive methodologies are adequate to account for sorption mechanisms they are not able to tackle durability and strength. Pritchard and Speake did manage to use water absorption data to predict polyester laminate property changes, but on an empirical (curve fitting) basis [14]. The mechanical parameters generally used to characterize degradation due to aging are tensile and flexural modulus and strength, and interlaminar shear strength. These values are then used to introduce safety factors into different aspects of design. However, the useful stress range for composite structures is limited by the appearance of damage. If structures are to be optimized for long term use at sea it is the influence of the environment on damage initiation and growth which must be quantified. These are also the parameters which need to be taken into account in materials selection but few data are available on which to base comparisons.

There have been some attempts to study how resistance to delamination of glass reinforced composites evolves with aging time in water. For example, Kenig et al. [15] and Pomiès et al. [16] studied the changes in shear fracture toughness $G_{I I c}$ with aging time in water. However, delamination is only one of the potential damage mechanisms. Microcracking and distributed damage may also occur and damage mechanics theories have been developed to characterize these mechanisms [17]. The main assumption is that the response of a damaged layer, at any load state, can be expressed in terms of elastic moduli degradation and inelastic strains due to damage and/or matrix plasticity, as shown in Figure 1. Degradation of the elastic moduli is expressed in terms of damage parameters that are functions of the associated thermodynamic forces. The modulus degradation parameters are internal variables, and the thermodynamic forces are the corresponding associated variables. The micro-level damage mechanisms taken into account are matrix micro-cracking, fiber debonding and fiber fracture. They are not identified explicitly in the mesoscale damage model; damage evolution is identified on the experimen-

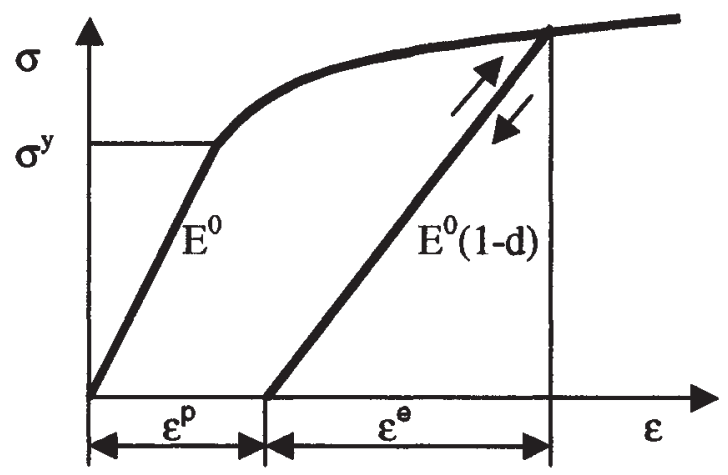

Figure 1. Schematic inelastic stress/strain response of damaged composite. 
tal stress-strain curves. As damage occurs, the material loses stiffness and exhibits nonlinear, inelastic response with permanent strains after unloading. Very little work has been performed on marine composites to evaluate the variation of damage parameters with aging, so far this approach has been mainly applied to high performance aerospace composites.

The aims of the present study are the following:

- to examine to what extent distilled water accelerated aging can be used to simulate the behaviour of typical marine composites in sea water

- to examine how the shear behaviour of composites with different matrix resins is affected by aging

- to assess the applicability of damage mechanics parameters to follow wet aging of marine composites

To achieve these objectives it was necessary to produce a large number of specimens at the same time from the same resin and fibre batches, to age them and to record their weights for a long period of time (over 18 months) and then to test their mechanical properties.

\section{MATERIALS STUDIED}

The materials studied here were chosen to represent the four most popular classes of resins currently used in marine applications:

- orthophthalic polyester (115 PA from Scott Bader), catalysed with 1.5\% wt. MEKP (methylethyl ketone peroxide)

- isophthalic polyester (491 PA from Scott Bader), catalysed with $1.5 \%$ wt. MEKP

- vinyl ester (Atlac 580 from DSM)

- DGEBA epoxy (SR1500 from Sicomin, amine hardener 2505)

Cast plates of the four resins were produced in $4 \mathrm{~mm}$ nominal thickness. Dogbone tensile specimens (form M1, ASTM 638M) were machined from the plates. Composite panels were produced by hand lay-up in a temperature $\left(20^{\circ} \mathrm{C}+/-2\right)$ and humidity $(50 \% \mathrm{RH}+/-5)$ controlled workshop at IFREMER in Brest. The reinforcement was six layers of $0^{\circ} / 90^{\circ}$ stitched fabric (reference LT600 from Sicomin SA, areal weight $566 \mathrm{~g} / \mathrm{m}^{2}$ ). The fibres are E-glass and their size is multicompatible. Vinyl ester and epoxy resin and composite panels were postcured after fabrication according to suppliers' recommendations at $90^{\circ} \mathrm{C}$ for 6 hours. The polyester panels were not postcured, as this is not done in practice, but the period of time between fabrication and immersion was at least 6 months. Dynamic mechanical analysis was performed on resin and composite samples in flexure in order to determine glass transition temperatures $\left(T_{g}\right)$. Samples $35 \mathrm{~mm}$ by $10 \mathrm{~mm}$ were heated in a TA Instruments DMA2980 at $5^{\circ} \mathrm{C} /$ minute and tested in single cantilever beam mode, the $T_{g}$ was defined as the temperature corresponding to the peak loss modu- 
Table 1. Materials.

\begin{tabular}{|c|c|c|c|c|c|}
\hline \multirow[b]{2}{*}{ Reference } & \multirow[b]{2}{*}{ Matrix } & \multirow[b]{2}{*}{$\begin{array}{c}\text { Cure } \\
\text { Condition }\end{array}$} & \multicolumn{2}{|c|}{ Resin Composite } & \multirow{2}{*}{$\begin{array}{c}\text { Fibre Mass } \\
\text { Content } \\
\text { (Burn-Off) \% }\end{array}$} \\
\hline & & & $T_{g}, \mathrm{C}^{\circ}$ & $\begin{array}{c}\text { Thickness, } \\
\text { mm }\end{array}$ & \\
\hline \multirow[t]{2}{*}{ ORTHO } & Orthophthalic & Air 6 months & 117 & 4.2 & $57 \pm 1$ \\
\hline & polyester & & 108 & 4.8 & \\
\hline \multirow[t]{2}{*}{ ISO } & Isophthalic & Air 6 months & 117 & 4.1 & $59 \pm 1$ \\
\hline & polyester & & 111 & 4.6 & \\
\hline \multirow[t]{2}{*}{ VINYL } & Vinyl ester & $6 \mathrm{~h} 90^{\circ} \mathrm{C}$ & 141 & 4.2 & $53 \pm 1$ \\
\hline & & & 142 & 5.4 & \\
\hline \multirow[t]{2}{*}{ EPOXY } & Epoxy & $6 \mathrm{~h} 90^{\circ} \mathrm{C}$ & 99 & 5.0 & $56 \pm 1$ \\
\hline & & & 97 & 5.1 & \\
\hline
\end{tabular}

lus. This is an arbitrary definition but is easier to identify from the measured curves than changes in storage modulus. Fibre fraction was determined by burn-off at $500^{\circ} \mathrm{C}$ for 6 hours. Table 1 shows results.

\section{AGING CONDITIONS}

In each case two of the mechanical test specimens were used to follow weight gain. Specimens were cut before aging, dried for 48 hours at $50^{\circ} \mathrm{C}$, weighed and placed in water. Immersion baths were kept at temperature to within $+/-2^{\circ} \mathrm{C}$. Accelerating temperature was chosen as $50^{\circ} \mathrm{C}$. A rule-of-thumb indicates that a $10^{\circ} \mathrm{C}$ rise in temperature causes a doubling of diffusion rate, so this was expected to correspond to an eight-fold acceleration compared to $20^{\circ} \mathrm{C}$ aging. Hence an 18 month immersion might be used to simulate a 12 year service life. This will be discussed below. The $50^{\circ} \mathrm{C}$ bath contained both the distilled water and the natural sea water specimens, the latter in a plastic container to avoid corrosion, so both sets of specimens underwent exactly the same temperature cycles. The sea water was taken directly from the Brest Estuary. Water was changed twice during the 18 month immersion. Specimen weight was recorded by removing specimens from the bath, wiping the edges and faces, weighing on a Sartorius balance and replacing in the bath. After immersion specimens were removed from the baths and tested immediately in the wet condition, as this corresponds closest to in-service conditions. However, in order to examine the reversibility of the aging phenomena some resin and composite specimens aged in sea water were dried in an oven for up to six months at $50^{\circ} \mathrm{C}$ and their desorption curves were recorded.

\section{MECHANICAL TESTING}

The mechanical tests performed were of two types, tensile loading for the resins 
and shear loading, via a tensile test on specimens cut at $45^{\circ}$ to the fibre direction (ASTM 3518) on the composite.

Resin tests were performed on an Instron $10 \mathrm{kN}$ capacity test frame. For most of the resin specimens the tensile elongation was measured with a conventional clip-on strain gauge extensometer, but for some tests a non-contact video extensometer was also used to avoid introducing stress concentrations. Crosshead displacement rate was $1 \mathrm{~mm} / \mathrm{minute}$.

Composite specimens were $20 \mathrm{~mm}$ wide and $250 \mathrm{~mm}$ long. They were clamped in MTS hydraulic grips in a $200 \mathrm{kN}$ capacity Roell \& Korthaus test machine. Longitudinal extension was measured by both the machine extensometer and an MTS clip-on biaxial extensometer. The latter also recorded transverse strain. Four composite specimens were tested for each condition (although several additional unaged specimens were tested initially to establish the loading cycle levels). The first specimen for each condition was loaded continuously to failure. The three remaining specimens were loaded with load-unload cycles at 75 and $90 \%$ of the failure load of the first specimen in order to study the damage parameters, as will be described below. Crosshead displacement rate was $2 \mathrm{~mm} / \mathrm{minute}$. All the force-strain data were recorded using a Solartron "Scorpio" data acquisition system for subsequent analysis. The $45^{\circ}$ tensile test was selected to follow changes with aging as it gives an indication of properties which are sensitive to both resin and interface performance. This test has been the subject of much discussion since its introduction by Rosen in 1972 for shear modulus measurement [18]. There is no completely satisfactory test for the determination of both shear modulus and strength, and several alternatives have been proposed for the latter [19]. The $45^{\circ}$ tensile test offers ease of fabrication and generally produces reliable modulus data. From the stress-strain curves recorded, an in-plane shear modulus, $G_{12}$, was evaluated using the slope of the shear stress (half the tensile stress) vs. shear strain (longitudinal strain minus transverse strain) curve over the shear strain range from 0 to $0.2 \%$. A shear strength $\tau_{12}$ was taken as the maximum stress, though it is recognized that the specimen failure does not result from pure shear so these values are labelled as "apparent shear strength."

\section{DAMAGE MECHANICS ANALYSIS}

The damage mechanics approach is introduced briefly. The procedure used to determine the damage mechanics parameters is described in the Appendix, where a detailed example is given. Further details are available in References [17,21-26]. The subscripts 1 and 2 designate the fiber direction and the transverse direction of the elementary ply respectively. The developments of the model are based upon the classical laminate theory in a plane stress state. The initial values of moduli (Figure 1) are indicated $E^{0}$. In the direction of the fibers, the behaviour is linear and brittle. In shear, progressive damage generates a non-linear behaviour. 


\section{Effective Stress and Response}

The effective stresses are the stresses acting over the damaged area that effectively resists the forces. In a general case, any stress component $\sigma_{i}$ can be affected by a damage parameter $d_{i}$ ranging from 0 (undamaged state) to 1 (macroscopic damage or failure). Here only the shear stress is affected by the damage variable $d$ :

$$
\tilde{\sigma}_{12}=\frac{\sigma_{12}}{(1-d)}
$$

The principle of strain equivalence states that "any deformation behaviour of a damaged material is represented by the constitutive laws of the virgin material in which the usual stress is replaced by the effective stress." Thus, the elastic constitutive equations for the damaged material in plane stress can be written as follows:

$$
\varepsilon_{12}^{e}=\frac{\sigma_{12}}{2 G_{12}^{0}(1-d)}
$$

From Equation (2), we see that the damage parameter $d$ is the internal variable representing the reduction of the shear modulus:

$$
G_{12}=G_{12}^{0}(1-d)
$$

\section{Thermodynamic Force and Progressive Damage Evolution Law}

The thermodynamic force, $Y_{d}$, associated with the internal damage variable $d$ can be related to the mean value of the strain energy density $E_{D}$ by the partial derivative, then in terms of the stress component and damage variable:

$$
Y_{d}=\frac{\sigma_{12}^{2}}{2 G_{12}^{0}(1-d)^{2}}
$$

In order to describe the evolution of damage a relation between $d$ and $Y_{d}$ is required. Damage will grow as $Y_{d}$ increases, but no further damage will occur for any value of $Y_{d}$ below a previous maximum value already reached. In the damage theory, the damage evolution law is a material property. Several models were applied and the best fitting law for our particular application is written in the form:

$$
d=\lambda\left(Y_{d}^{n}-Y_{o}^{n}\right) \quad \text { with } n=0.25
$$

where $\lambda$ is the non-zero damage evolution parameter determined from experimental results. 


\section{Inelastic Strains Coupled with Damage and Evolution Law}

As depicted in Figure 1, the type of composite studied here exhibits a non-linear response when stressed beyond some elastic limit stress, $\sigma^{y}$. When the material is completely unloaded from a stress in excess of this limit, there are inelastic (permanent) strains $\varepsilon^{p}$. As glass fibres exhibit a linear, elastic response, plasticity effects are associated with the matrix, and are most significant under a shear stress state. The formalism for the inelastic strains is that of classical plasticity, with an elastic domain function depending on the current effective stress $\tilde{\sigma}_{12}$, and the accumulated effective inelastic strain $\tilde{p}_{\dot{\tilde{\varepsilon}}}$ based upon the use of the effective inelastic shear strain rate $\dot{\tilde{\varepsilon}}_{12}^{p}$ :

$$
\dot{\tilde{p}}=2 \dot{\tilde{\varepsilon}}_{12}^{p} \quad \text { with } \quad \dot{\tilde{\varepsilon}}_{12}^{p}=\dot{\varepsilon}_{12}^{p}(1-d)
$$

$\tilde{p}$ can also be expressed in the form:

$$
\tilde{p}=\int_{0}^{\varepsilon_{12}^{p}} 2(1-d) d \varepsilon_{12}^{p}
$$

For no (or negligible) inelastic strains in the fibre direction and in the transverse direction, the elasticity domain function is defined by:

$$
f(\sigma, R)=\tilde{\sigma}_{12}-R(\tilde{p})-R_{o} \leq 0
$$

where $R(\tilde{p})$ is a function of $\tilde{p} . R(p)$ is the limit of the elastic domain expressed as an effective stress $\left(\sigma_{12} /(1-d)\right)$. In the simplified model used here $R_{o}$ is set to zero. A typical result from previous applications of this Damage Theory on glass/epoxy composites is expressed as follows, where $\beta$ is a material parameter [25]:

$$
R(\tilde{p})=\beta \sqrt{\tilde{p}}
$$

\section{RESULTS}

\section{Resin Weight Gain}

The weight changes of resin specimens are shown in Figure 2. Weight gains were measured on two specimens in each case. The aging period in sea water is at least 18 months for all but the orthophthalic polyester, all the $20^{\circ} \mathrm{C}$ specimens were left for three and a half years. These plots show a number of features. First, the resins are quite "well-behaved" at $20^{\circ} \mathrm{C}$. In general they show near-Fickian behaviour, all except the epoxy reaching a knee followed by a slowly increasing plateau region within 6 months at this temperature. The epoxy weight is still increasing after 18 months at $20^{\circ} \mathrm{C}$, but after 42 months weight gains have stabilized. Increasing 


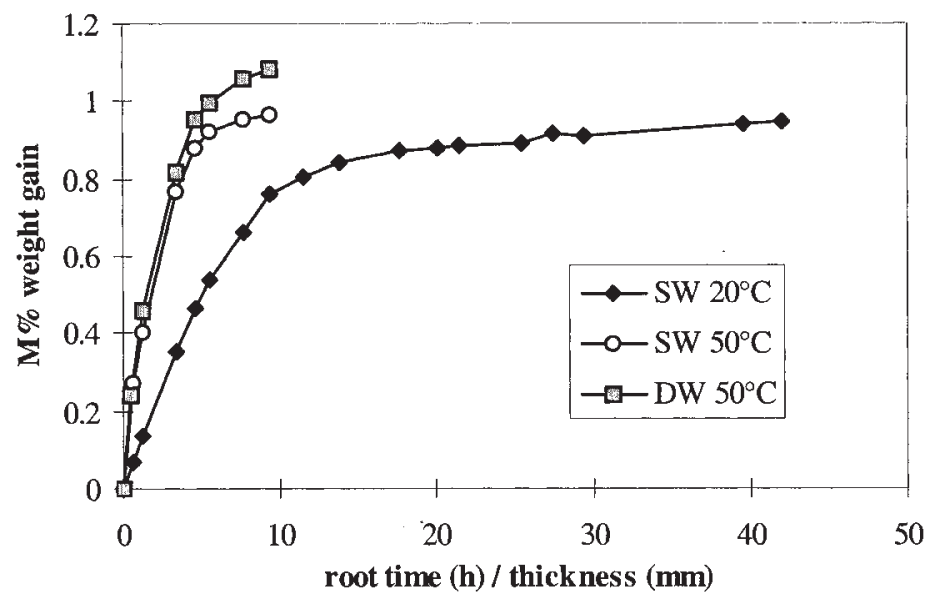

(a)

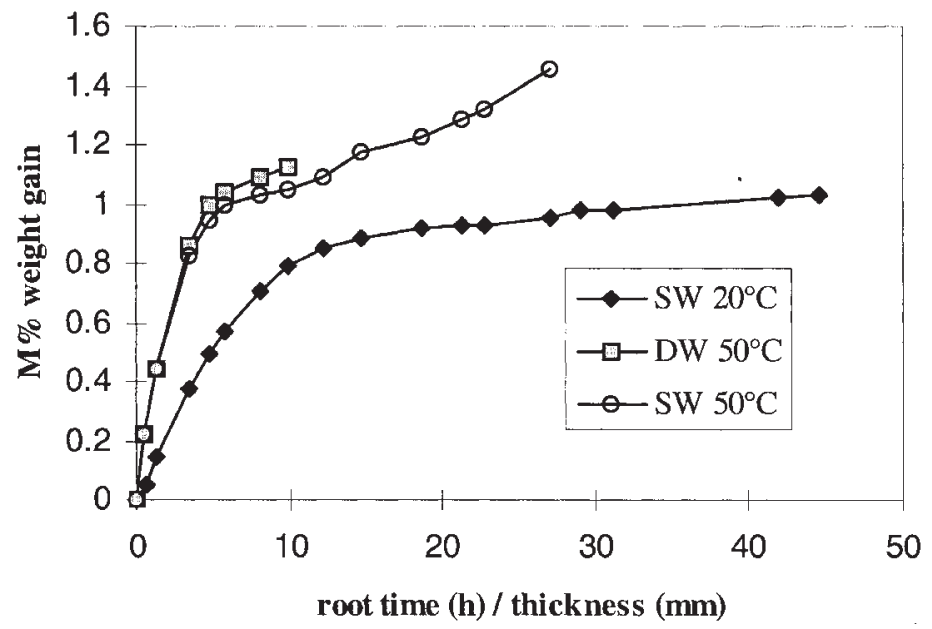

(b)

Figure 2. Resin weight gains: (a) orthophthalic polyester, (b) isophthalic polyester, (c) vinyl ester and (d) epoxy. 


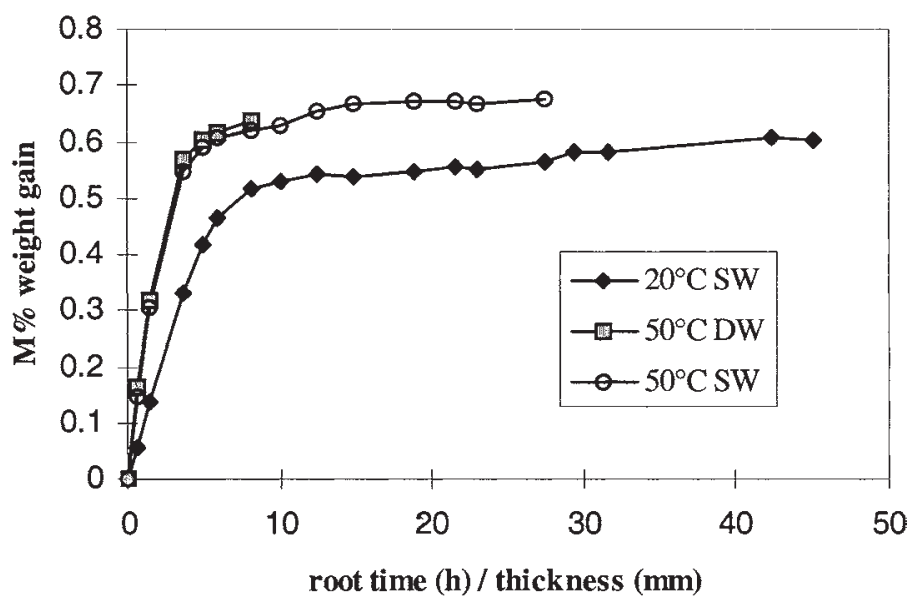

(c)

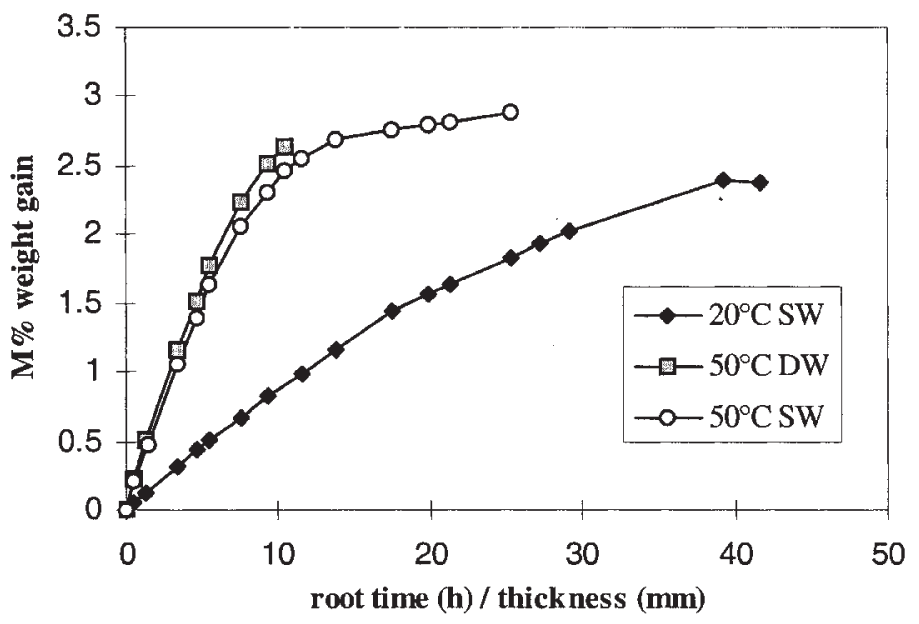

(d)

Figure 2 (continued). Resin weight gains: (a) orthophthalic polyester, (b) isophthalic polyester, (c) vinyl ester and (d) epoxy. 
the temperature to $50^{\circ} \mathrm{C}$ increases the rate of weight gain as expected for all resins. The time to reach a given weight gain in the initial linear region is reduced by a factor of 6 to 12 for the polyesters, about 6 for the vinyl ester and about 12 for the epoxy. Table 2 shows initial slopes. The weight gains at $50^{\circ} \mathrm{C}$ are similar for sea water and distilled water, the latter being reached slightly faster, and the plateau levels reached were slightly higher in distilled water tests when these specimens were removed after 3 months. The $50^{\circ} \mathrm{C}$ sea water orthophthalic polyester tests were also stopped but the measurements continued on the other three materials. Removing the specimens, after 18 months in $50^{\circ} \mathrm{C}$ sea water, the isophthalic polyester has started to degrade and weight is increasing rapidly. The vinyl ester specimens appear to have stabilized at a slightly higher saturation level in sea water at the higher temperature, with respect to the $20^{\circ} \mathrm{C}$ value, but the weight gains are low for this material so differences are quite small.

One specimen of each resin aged in sea water at $20^{\circ} \mathrm{C}$ for 42 months was then dried in an oven at $50^{\circ} \mathrm{C}$. The desorption curves are shown in Figure 3. The desorption rates are very similar to the absorption curves at $50^{\circ} \mathrm{C}$. The polyesters and the vinyl ester return to their initial weight after 1 month, while the epoxy takes rather longer, around 4 months. These plots suggest that at this temperature in sea water there is no significant degradation of any of the resins after three and a half years' immersion.

\section{Composite Weight Gain}

Figures 4(a)-(d) show the weight changes of the composites for the three immersion conditions. A number of observations may be made. First, the behaviour in sea water at $20^{\circ} \mathrm{C}$ is reasonably consistent with the unreinforced resin behaviour under these conditions, but all the accelerated tests show anomalies. In the case of the polyesters these may be related to degradation, but it is apparent that there is a very significant difference between distilled water and sea water in terms of

Table 2. Initial diffusion rates [M\% $\times$ thickness in $\mathrm{mm} /$ root time (hours)] for resins/(composites) in $50^{\circ} \mathrm{C}$ distilled water (DW) and natural sea water (SW) at $20^{\circ} \mathrm{C}$ and $50^{\circ} \mathrm{C}$.

\begin{tabular}{lcccc}
\hline & ORTHO & ISO & VINYL & EPOXY \\
\hline $20^{\circ} \mathrm{C} \mathrm{SW}$ & 0.10 & 0.10 & 0.09 & 0.09 \\
& $(0.09)$ & $(0.15)$ & $(0.07)$ & $(0.12)$ \\
$50^{\circ} \mathrm{C} \mathrm{SW}$ & 0.25 & 0.34 & 0.21 & 0.30 \\
& $(0.17)$ & $(0.21)$ & $(0.09)$ & $(0.20)$ \\
$50^{\circ} \mathrm{C} \mathrm{DW}$ & 0.38 & 0.34 & 0.22 & 0.33 \\
& $(0.21)$ & $(0.22)$ & $(0.08)$ & $(0.23)$ \\
\hline
\end{tabular}




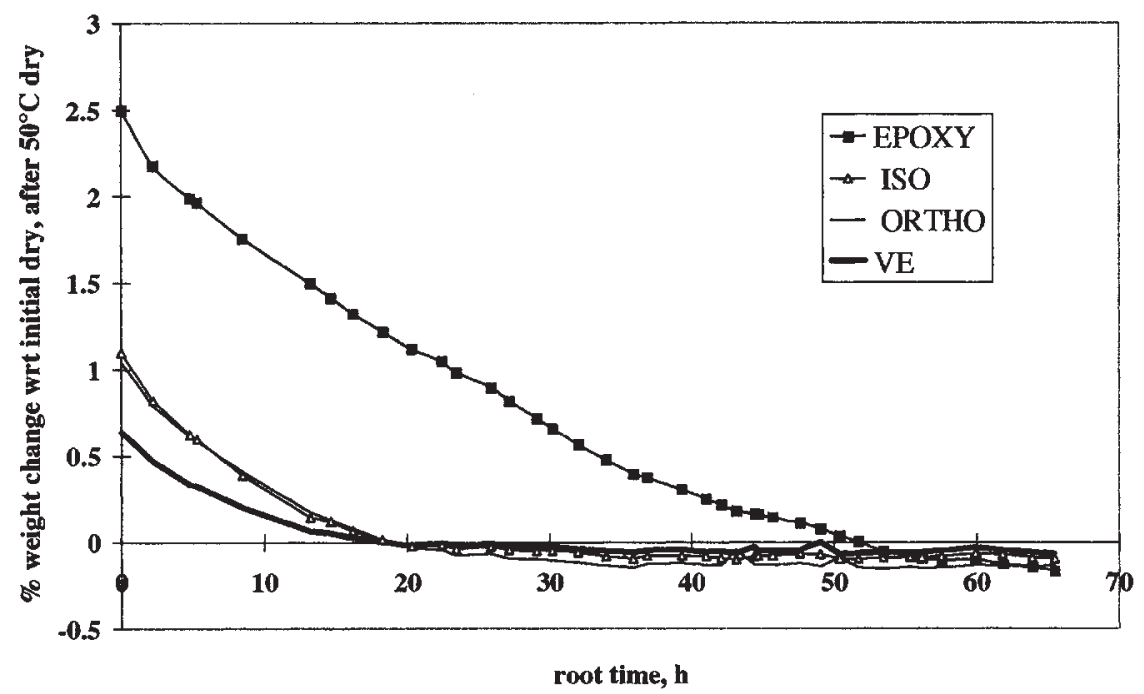

Figure 3. Drying of resins at $50^{\circ} \mathrm{C}$ after 42 months aging at $20^{\circ} \mathrm{C} \mathrm{SW}$.

weight gain for all the materials. The effect of large salt ions in blocking diffusion passages may be partly responsible for this difference but it has significant consequences for the use of distilled water aging to simulate the marine environment. For example, aging of isophthalic polyester in distilled water results in a secondary weight gain increase after about a month which is not observed in sea water even after 18 months. Similar dramatic increases in weight are noted for the vinyl ester and epoxy composites after one to three months at $50^{\circ} \mathrm{C}$ in distilled water. As Figure 2 shows no evidence that these two resins might degrade in this period this suggests that it is the fibre-matrix interface which is more susceptible to distilled water than to sea water. Use of distilled water as an "accelerating" factor to simulate service in a marine environment is therefore producing an effect which will not necessarily be found in a marine environment. The influence of the aging medium on mechanical property degradation will be discussed below.

It is also interesting to look at the desorption curves during drying for one month at $50^{\circ} \mathrm{C}$ of four other specimens of each composite which had been aged for 18 months in sea water at $50^{\circ} \mathrm{C}$ (Figure 5). Error bars indicating maximum and minimum values are shown to give an idea of scatter, which was very low in most cases. The residual weights after one month are very different for the four composites. The polyesters both lose weight on drying, indicating that short molecules have been extracted during aging and that hydrolysis has probably occurred. The vinyl ester composite water absorption is nearly completely reversible, while the epoxy has not stabilized and still shows a significant residual weight gain after a month at 


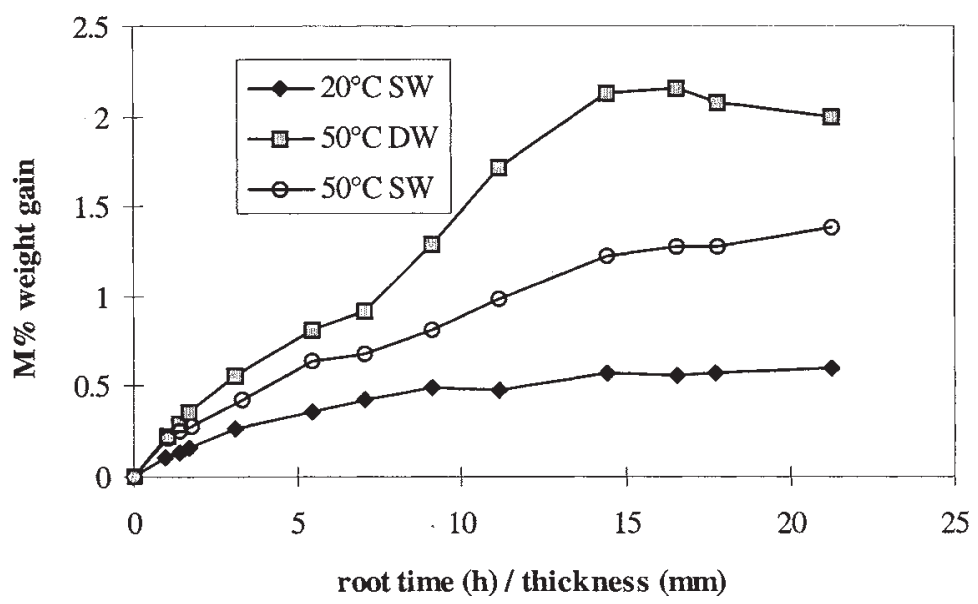

(a)

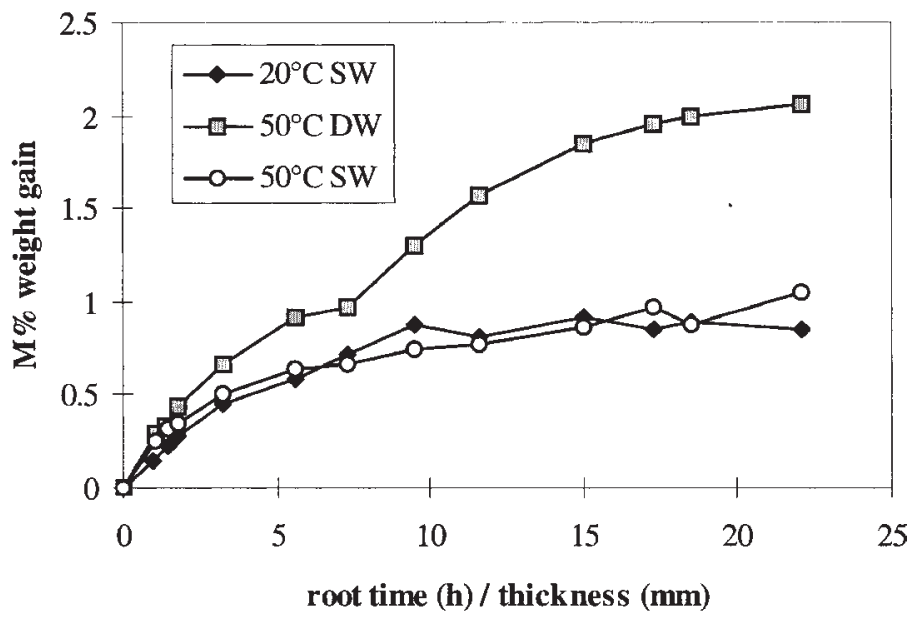

(b)

Figure 4. Composite weight gains: (a) orthophthalic polyester, (b) isophthalic polyester, (c) vinyl ester and (d) epoxy. 


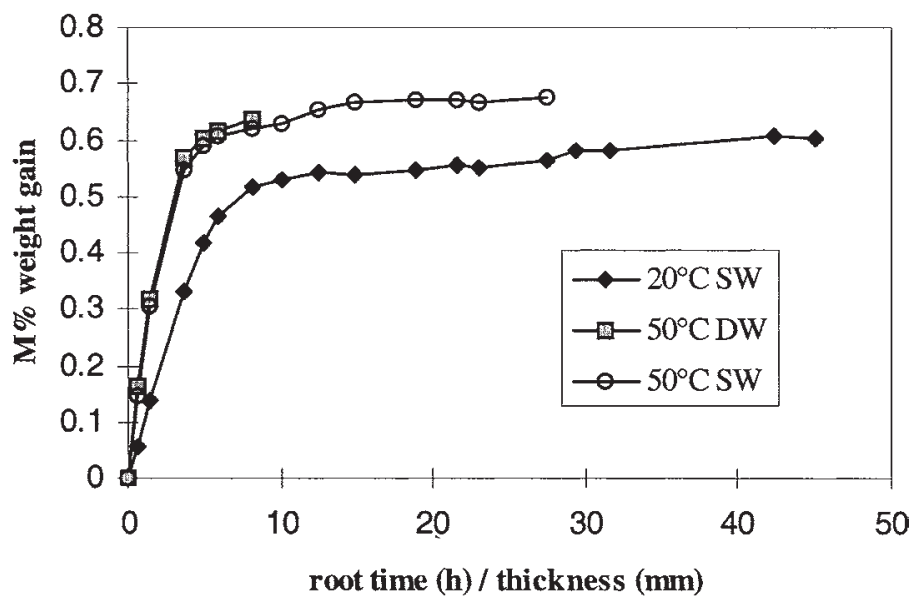

(c)

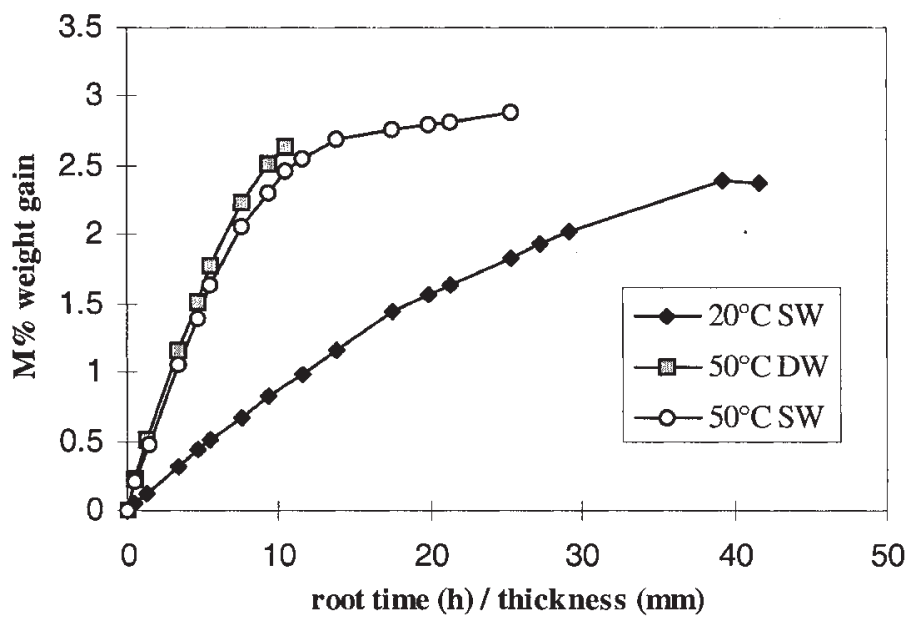

(d)

Figure 4 (continued). Composite weight gains: (a) orthophthalic polyester, (b) isophthalic polyester, (c) vinyl ester and (d) epoxy. 


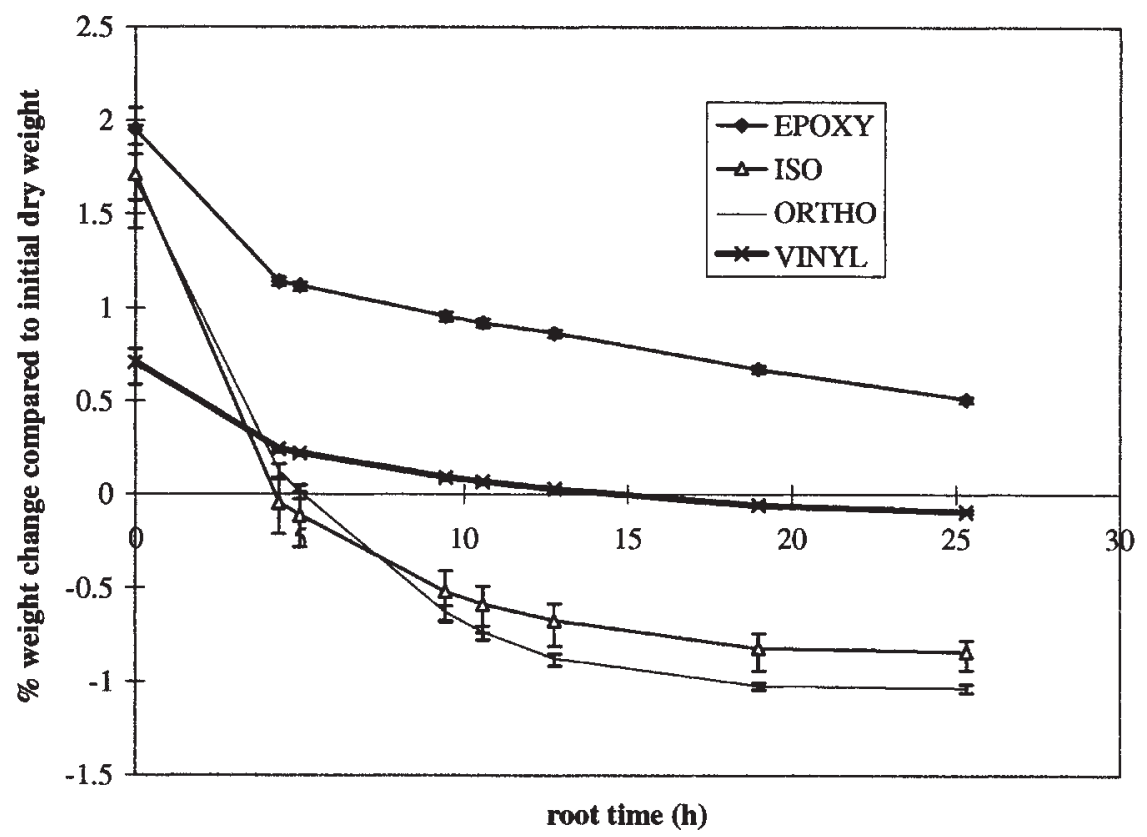

Figure 5. Drying of composites in oven at $50^{\circ} \mathrm{C}$, after 18 months aging in sea water at $50^{\circ} \mathrm{C}$.

$50^{\circ} \mathrm{C}$. It is interesting to note that the weight gains before drying for these specimens, which were left for 18 months in sea water are rather higher than those of the specimens which had been removed periodically for weighing during the 18 month period (Figure 4). This may be due to the presence of a biofilm on the specimen surfaces.

\section{Tensile Tests on Resins}

Some tensile tests were performed on unaged resin specimens. Then, for all but the orthophthalic resin, tensile tests were performed in air after 18 months' sea water aging (in the same $50^{\circ} \mathrm{C}$ tank as the composite specimens). These tests give an indication of how the matrix properties evolve. Moduli were measured on the same specimens before and after drying, tensile strengths were only obtained after drying. Figure 6 shows typical reference (unaged) stress-strain plots. The unaged epoxy is significantly more ductile than the other resins, as has been noted in a previous study of the fracture toughness of these same resin systems [20]. It should be noted however, that the resin strength values are very sensitive to defects and higher strength values were found in that previous study, particularly on the vinyl ester, by testing smaller specimens. Figures 7(a) and 7(b) show how moduli and 


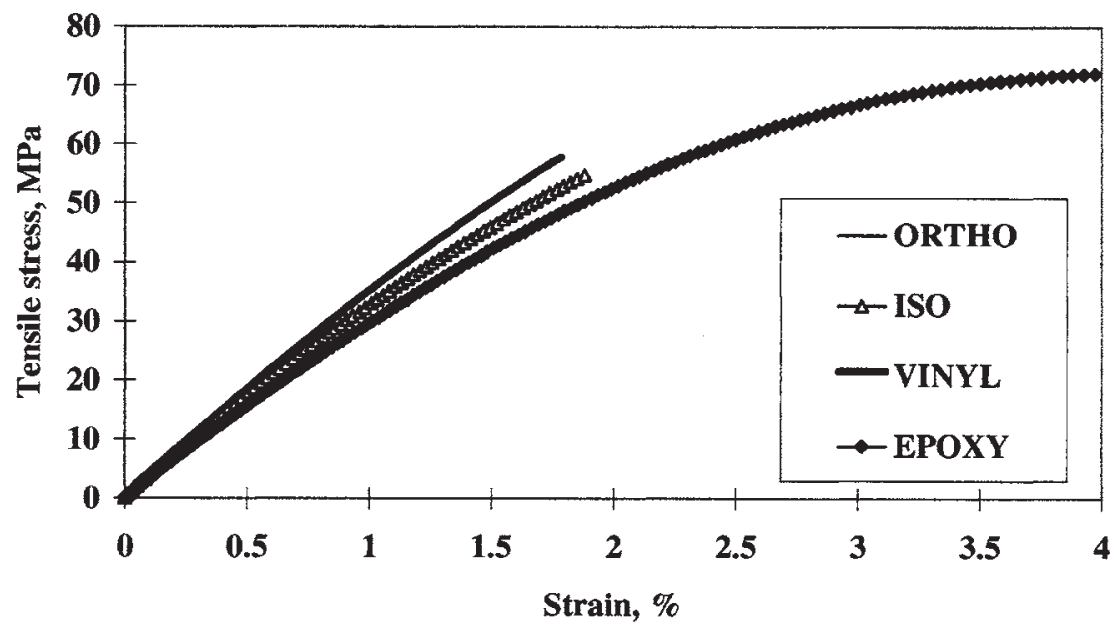

Figure 6. Tensile stress-strain plots, unaged resins (ortho- and iso- polyesters superpose).

strength vary after aging. The modulus of the wet polyester decreases after aging, but after drying it is slightly higher than the reference value so presumably some post-curing or physical aging has taken place. The tensile moduli of the vinyl ester and epoxy show little effect of aging. The tensile strengths show more significant effects. The polyester loses about $20 \%$ of the initial value, the vinyl ester is unaf-

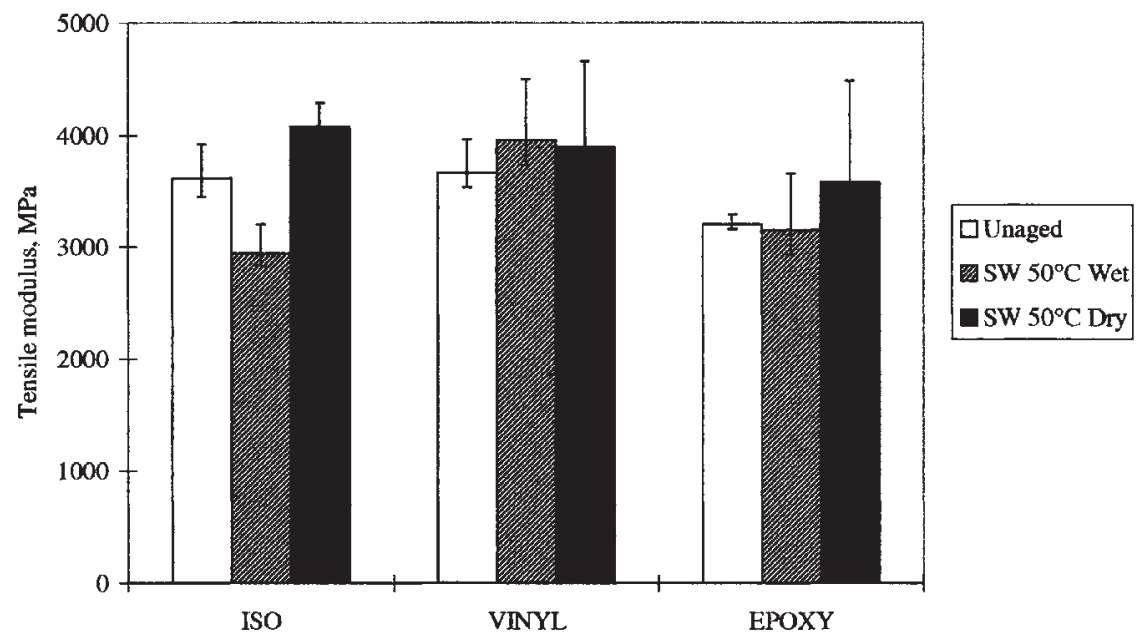

(a)

Figure 7. Influence of 18 months' sea water aging on resin properties: (a) modulus and (b) tensile strength. 


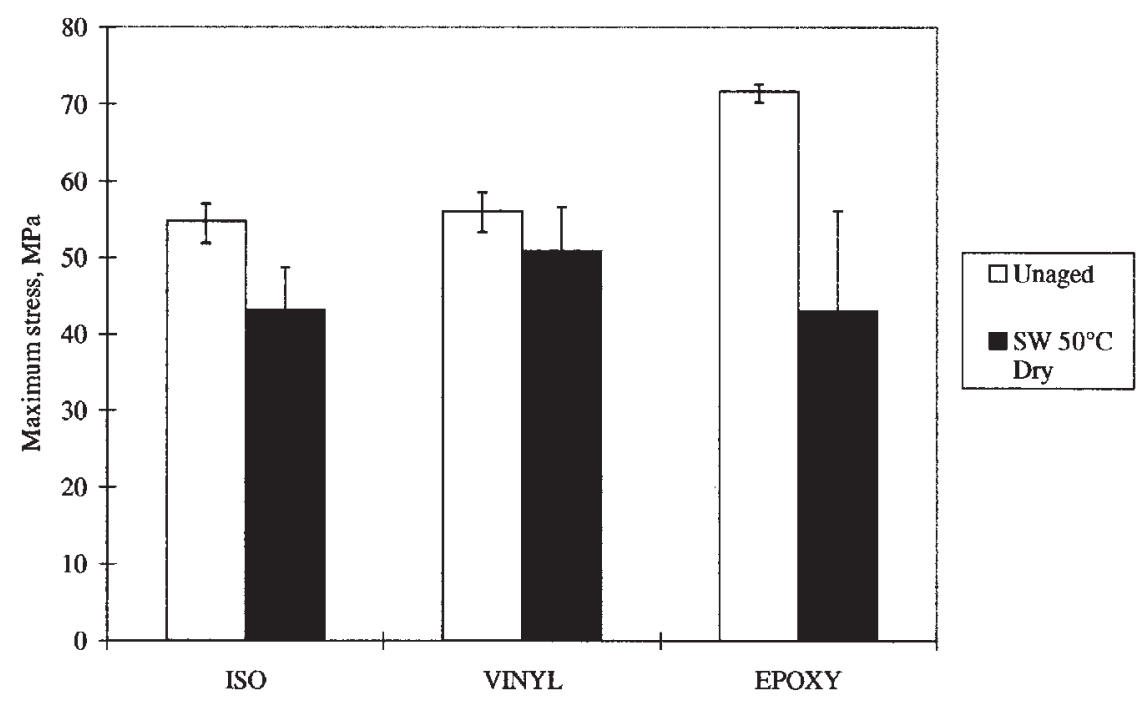

(b)

Figure 7 (continued). Influence of 18 months' sea water aging on resin properties: (a) modulus and (b) tensile strength.

fected and the tensile strength of the epoxy, initially significantly higher than that of the other resins, drops by about $40 \%$ after aging. However, even after aging the epoxy tensile strength is still at a similar level to those of the other resins, and it should be noted that the epoxy composite has not been completely dried.

\section{Composite $45^{\circ}$ Tensile Tests}

The tests on composites yield four values: (1) shear modulus, $G_{12}$; (2) apparent shear strength, $\tau_{12} ;(3)$ damage mechanics parameter $\lambda$, and plasticity parameter $\beta$. Examples of reference stress-strain plots for each composite material are shown in Figure 8 . The higher ductility in tension of the epoxy resin is clearly revealed in the composite shear behaviour, while the vinyl ester reaches the highest apparent shear strength.

\section{SHEAR MODULUS}

The values of the shear moduli for the four materials are presented in Table 3. Figure 9 presents the percentage changes in mean values for each material as a function of aging. The shear moduli of the four materials before aging are similar but after aging the moduli of the polyester composites decrease significantly. Results after drying show that this is partly reversible but a significant drop remains 


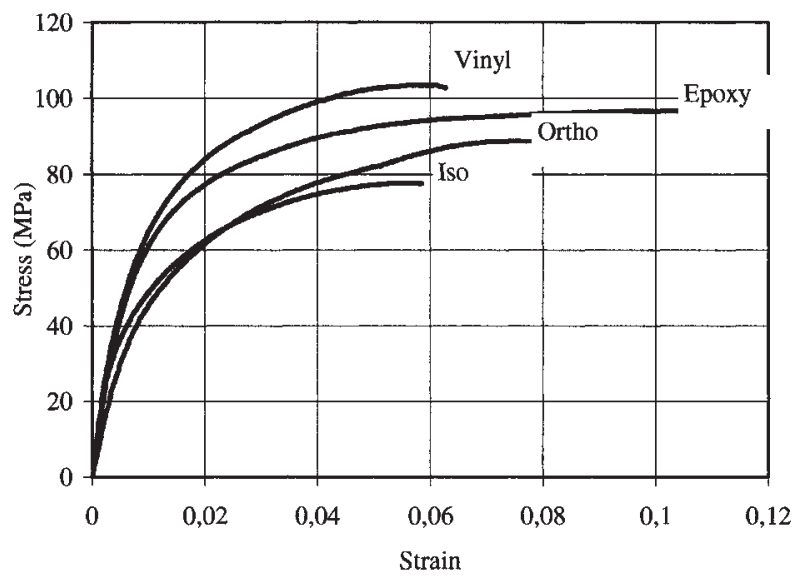

Figure 8. Shear stress-strain plots, unaged composites.

even after drying. The epoxy and vinyl ester composites show much smaller effects of aging. There is a small difference between aging in sea water and aging in distilled water for the $G_{12}$ value, the distilled water is slightly more severe.

\section{APPARENT SHEAR STRENGTH}

The values of apparent in-plane shear strength are also shown in Table 3 and presented in Figure 10. Once again large, partly reversible drops are noted for the polyesters. There is again a small difference between aging in sea water and distilled water. The values shown in Figures 9 and 10 and Table 3 are those most frequently used to characterize the shear behaviour. However, given the very non-linear nature of the stress-strain curves (Figure 8) the conventional parameters of initial modulus and apparent shear strength are clearly inadequate to characterize the changes in the materials after aging. A more complete description of the stress-strain behaviour might therefore prove useful, and this is explored in the next section.

\section{DAMAGE CHARACTERIZATION}

\section{Unaged Specimens}

A first series of tests was run on two unaged specimens of each composite in order to examine the range of linearity of the specimens and to select suitable loads for cycling. This is discussed in more detail in the Appendix but it was clear that cycling above a stress of $20 \mathrm{MPa}$ produces measurable non-linear behaviour. The resulting damage development plots indicated damage thresholds which are simi- 
Table 3. Mean (minimum-maximum) values of shear modulus and apparent shear strength, composites, tensile test at $45^{\circ}$.

\begin{tabular}{lcccc}
\hline Condition & ORTHO & ISO & VINYL & EPOXY \\
\hline \multicolumn{4}{c}{ Shear Modulus, MPa } \\
\hline Unaged & 3600 & 3320 & 3440 & 3050 \\
& $(3540-3630)$ & $(3260-3390)$ & $(3350-3570)$ & $(2980-3170)$ \\
$20^{\circ} \mathrm{C}$ SW 18 m W & 3080 & 2670 & 3030 & 2820 \\
& $(3030-3180)$ & $(2550-2740)$ & $(2890-3150)$ & $(2770-2850)$ \\
$50^{\circ} \mathrm{C}$ DW 18 m W & 1730 & 1790 & 2810 & 2390 \\
& $(1630-1810)$ & $(1750-1850)$ & $(2630-2930)$ & $(2280-2480)$ \\
$50^{\circ} \mathrm{C}$ SW 18 m W & 1790 & 1900 & 2890 & 2490 \\
& $(1770-1840)$ & $(1860-1950)$ & $(2810-2960)$ & $(2420-2540)$ \\
$50^{\circ} \mathrm{C}$ SW 18 m D & 2630 & 2620 & 3130 & 2920 \\
& $(2500-2760)$ & $(2540-2800)$ & $(3050-3190)$ & $(2880-2950)$ \\
\hline & Apparent Shear Strength, MPa & 49 \\
\hline Unaged & 45 & 41 & 53 & $(48-50)$ \\
& $(44-46)$ & $(39-42)$ & $(50-56)$ & 45 \\
$20^{\circ} \mathrm{C}$ SW 18 m W & 41 & 36 & 48 & $(45-45)$ \\
& $(40-41)$ & $(34-37)$ & $(47-48)$ & 37 \\
$50^{\circ} \mathrm{C}$ DW 18 m W & 27 & 27 & 40 & $(36-37)$ \\
& $(26-28)$ & $(25-29)$ & $(37-42)$ & 38 \\
$50^{\circ} \mathrm{C}$ SW 18 m W & 28 & 28 & 41 & $(37-38)$ \\
& $(27-29)$ & $(26-29)$ & $(39-42)$ & 44 \\
$50^{\circ} \mathrm{C}$ SW 18 m D & 37 & 35 & 48 & $(43-45)$ \\
& $(36-38)$ & $(33-38)$ & $(46-49)$ & \\
\hline
\end{tabular}

SW: sea water, DW: distilled water. Test conditions: W: wet, D: dry. 


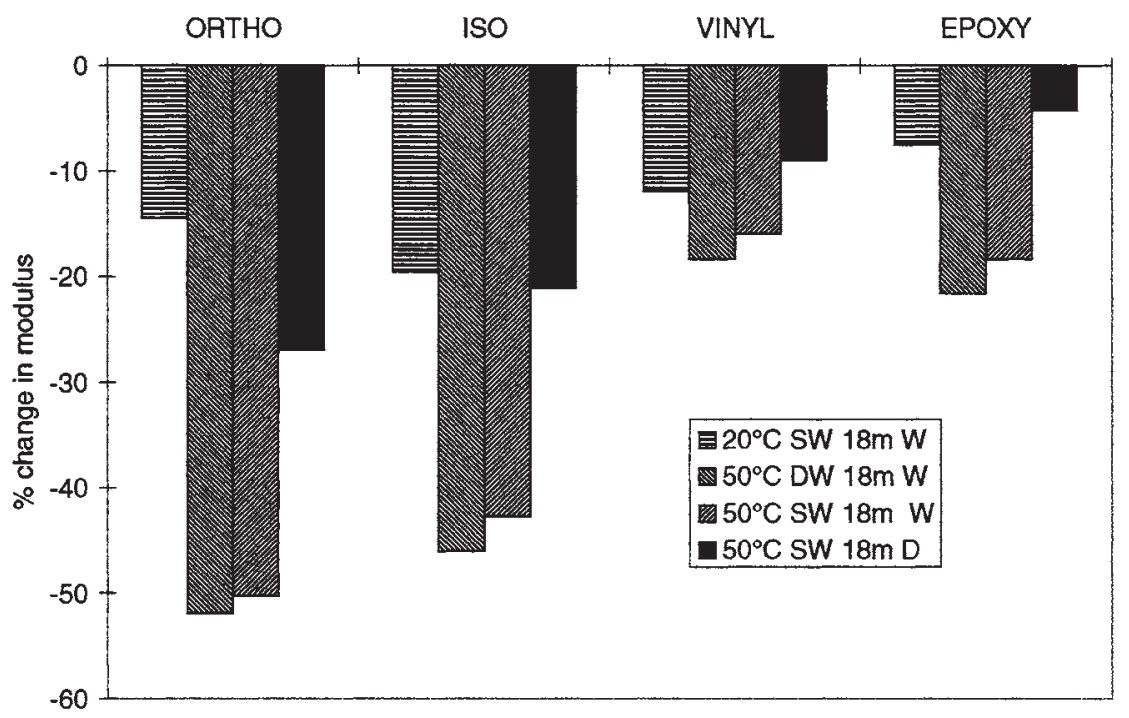

Figure 9. Percentage changes in mean shear moduli after aging.

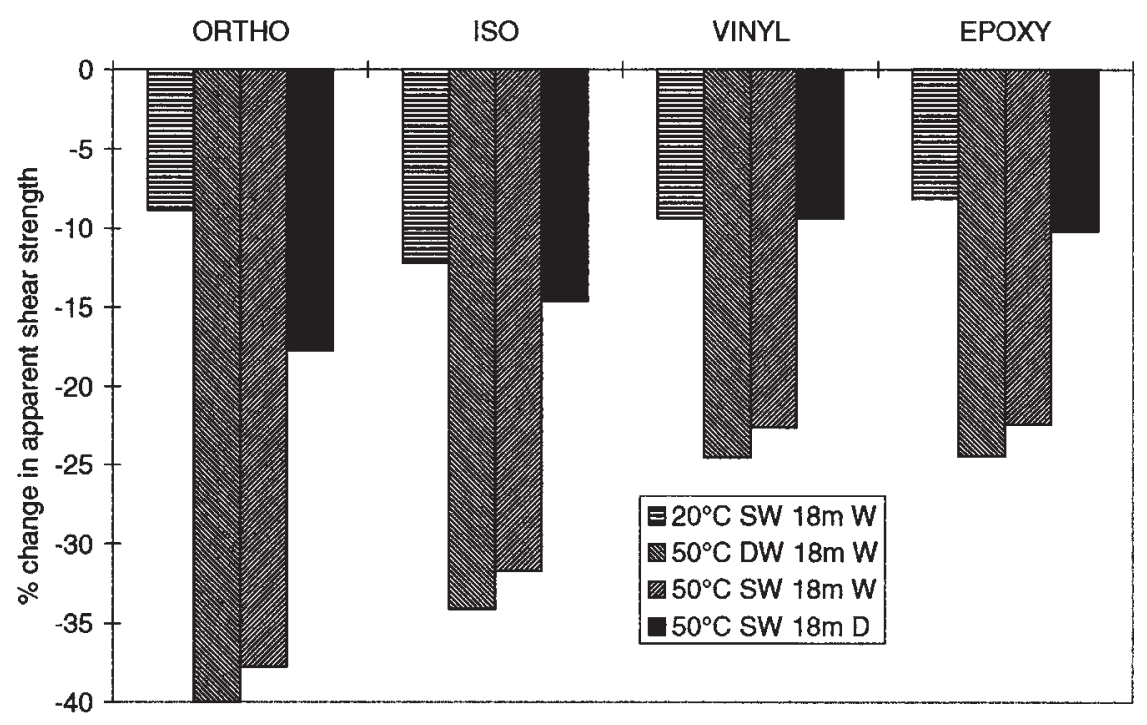

Figure 10. Percentage changes in mean apparent shear strength after aging. 
lar in the four materials [Figures 11(a) and 11(b)] with a value of $Y_{0}$ around 0.15 $\mathrm{MPa}$, which corresponds to a longitudinal tensile stress of $20 \mathrm{MPa}$, but there are some differences in the subsequent damage development behaviour. In particular the higher damage and plasticity development rates of the two polyester composites are clearly revealed. Each of these specimens was also instrumented with two acoustic emission transducers to establish qualitatively whether the onset of non-linear stress-strain behaviour could be related to damage rather than non-linear elasticity or viscoelasticity. It is clear that a much more detailed study is required if particular failure mechanisms are to be assigned to acoustic emission parameters and this was not the aim here. However, in all materials acoustic emission was recorded at a very early stage, from around $10 \mathrm{MPa}$ axial stress, and re-appeared when reloading above the previous cycle maximum load value. This does not prove that all the inelastic behaviour is due to damage but does indicate that damage contributes to it from an early stage.

\section{Influence of Aging}

For each aging condition the first specimen was loaded continuously to failure, then two cyclic loading levels were applied to each of the three remaining specimens to allow the damage parameters to be determined, namely 75 and $90 \%$ of the failure load (Figure 12). All six cycles for the three specimens were then used in the analysis. Figures 13 and 14 and Table 4 show the results for each material in terms of the damage parameters $\lambda$ and $\beta$. These results show that the damage parameter is not significantly affected by the aging process but that the plasticity parameter $\beta$ is strongly affected. The lower the $\beta$ value the more plasticity occurs be-

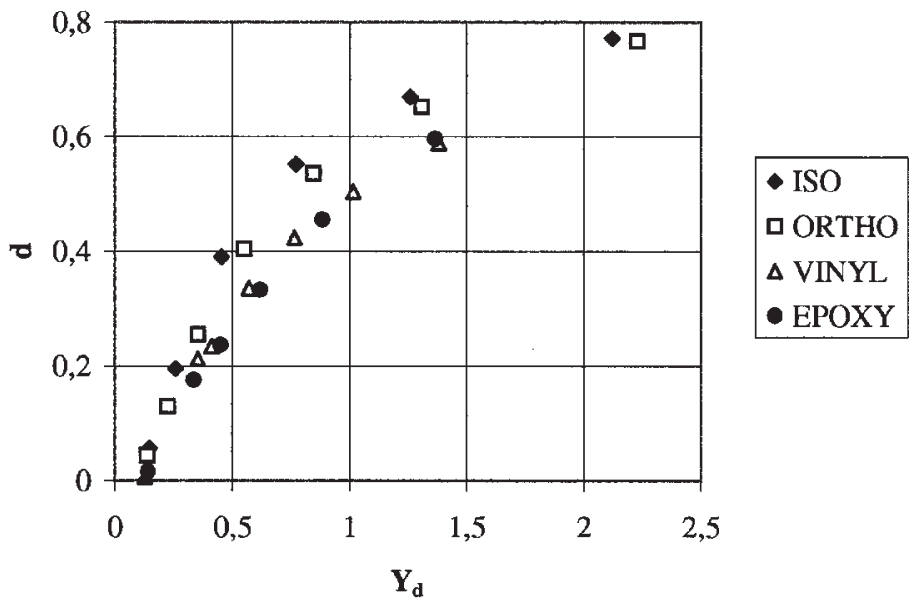

(a)

Figure 11. (a) Damage development and (b) plasticity plots, unaged specimens. 


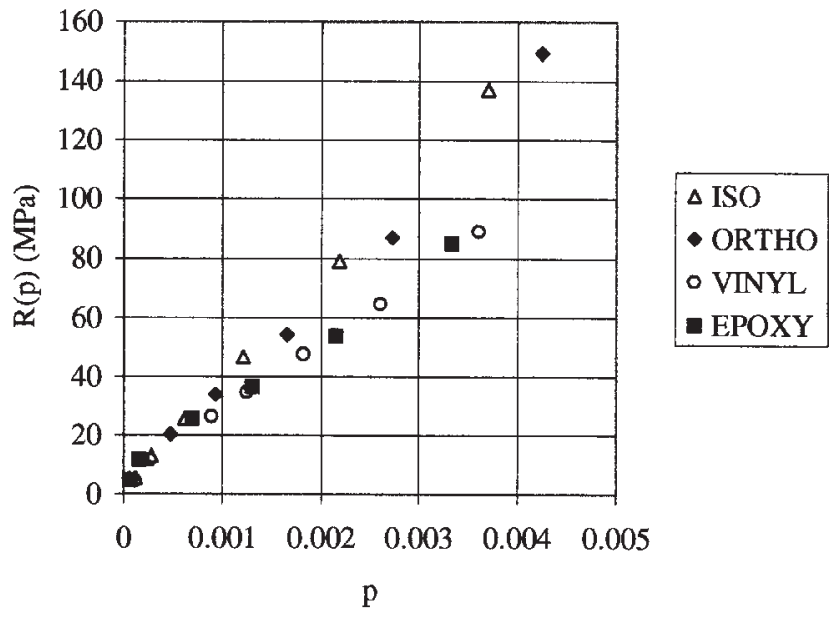

(b)

Figure 11 (continued). (a) Damage development and (b) plasticity plots, unaged specimens.

$20^{\circ} \mathrm{C} \mathrm{SW} 18 \mathrm{~m}$ W / Unaged

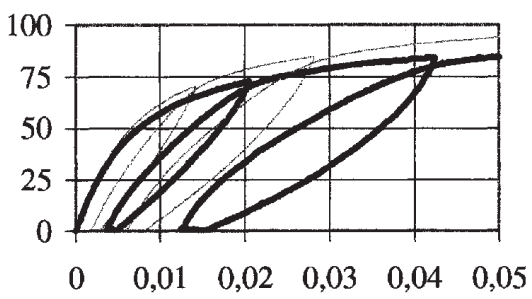

$50^{\circ} \mathrm{C}$ DW $18 \mathrm{~m}$ W/ Unaged

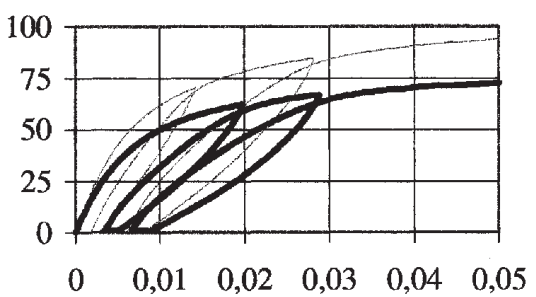

$50^{\circ} \mathrm{C} \mathrm{SW} 18 \mathrm{~m}$ D / Unaged

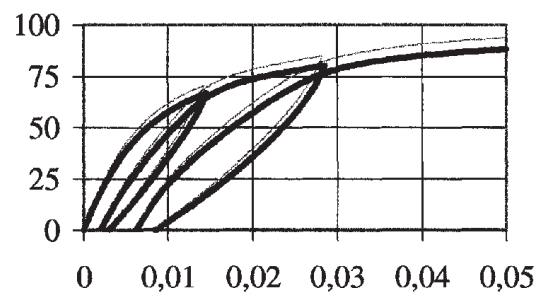

$50^{\circ} \mathrm{C} \mathrm{SW} 18 \mathrm{~m}$ W/ Unaged

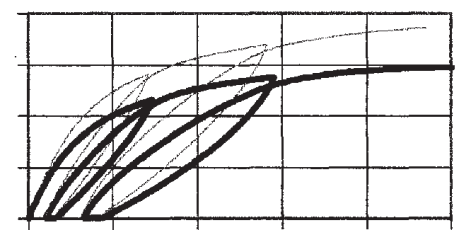

Figure 12. Glass/epoxy composite. Axial stress (MPa)-axial strain plots, examples of loadunload cycles for aged specimens, compared in each case to unaged response. 


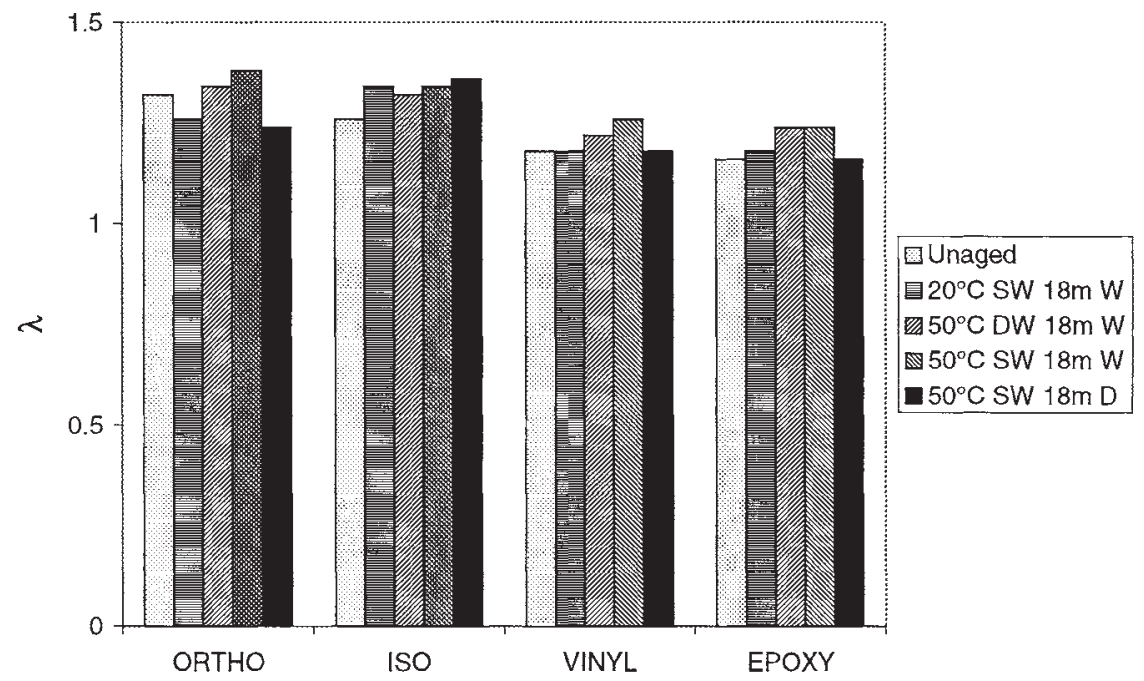

Figure 13. Influence of aging on damage parameter $\lambda\left(\mathrm{mm}^{2} / \mathrm{N}\right)^{0.25}$.

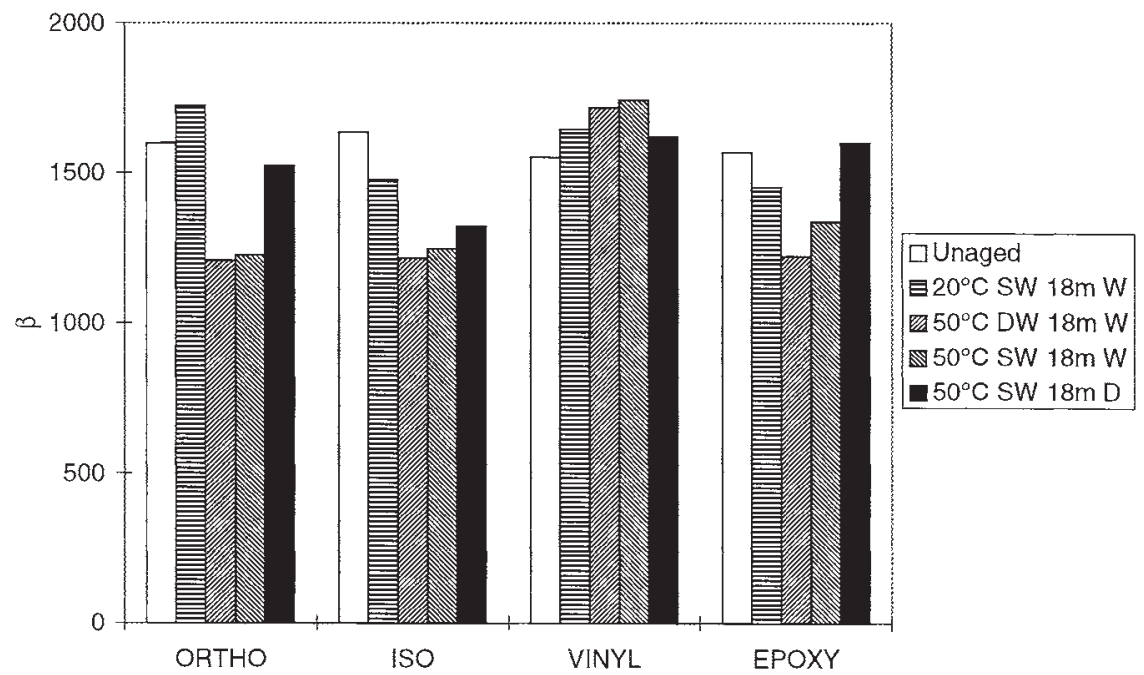

Figure 14. Influence of aging on plasticity parameter $\beta(\mathrm{MPa})$. 
Table 4. Damage parameter $\lambda$ and plasticity parameter $\beta$.

\begin{tabular}{|c|c|c|c|c|}
\hline & ORTHO & ISO & VINYL & EPOXY \\
\hline \multicolumn{5}{|c|}{ Damage Parameter $\lambda(\mathrm{MPa})^{-1 / 4}$} \\
\hline Unaged & 1.32 & 1.26 & 1.18 & 1.16 \\
\hline $20^{\circ} \mathrm{C} \mathrm{SW} 18 \mathrm{~m} \mathrm{~W}$ & 1.26 & 1.34 & 1.18 & 1.18 \\
\hline $50^{\circ} \mathrm{C}$ DW $18 \mathrm{~m} \mathrm{~W}$ & 1.34 & 1.32 & 1.22 & 1.24 \\
\hline $50^{\circ} \mathrm{C} \mathrm{SW} 18 \mathrm{~m} \mathrm{~W}$ & 1.38 & 1.34 & 1.26 & 1.24 \\
\hline $50^{\circ} \mathrm{C} \mathrm{SW} 18 \mathrm{~m} \mathrm{D}$ & 1.24 & 1.36 & 1.18 & 1.16 \\
\hline \multicolumn{5}{|c|}{ Plasticity Parameter $\beta, \mathrm{MPa}$} \\
\hline Unaged & 1599 & 1636 & 1552 & 1569 \\
\hline $20^{\circ} \mathrm{C} \mathrm{SW} 18 \mathrm{~m} \mathrm{~W}$ & 1725 & 1478 & 1646 & 1454 \\
\hline $50^{\circ} \mathrm{C} \mathrm{DW} 18 \mathrm{~m} \mathrm{~W}$ & 1209 & 1217 & 1716 & 1223 \\
\hline $50^{\circ} \mathrm{C} \mathrm{SW} 18 \mathrm{~m} \mathrm{~W}$ & 1227 & 1248 & 1744 & 1339 \\
\hline $50^{\circ} \mathrm{C} \mathrm{SW} 18 \mathrm{~m} \mathrm{D}$ & 1526 & 1323 & 1623 & 1603 \\
\hline
\end{tabular}

fore failure. For the isophthalic polyester the reduction in $\beta$ is irreversible after drying, while for the epoxy it is completely recovered after drying for one month [even though drying is not complete (Figure 8)]. There is again a consistent but small difference between distilled water and sea water aging, the former appearing slightly more severe. The shear behaviour of the vinyl ester composite is the least sensitive to aging and the plasticity parameter increases slightly after aging for this material. Thus although the apparent shear strength drops by $25 \%$ after $50^{\circ} \mathrm{C}$ aging the plasticity before failure is not affected. This may have significant consequences in terms of damage tolerance, and requires further study.

These first results suggest that this damage mechanics characterization can supply complementary information to the more traditional parameters used to follow aging. Although it lengthens the test procedure slightly, even in this simplified model form, it does allow the complete material stress-strain response to be modelled, and the parameters which emerge can be integrated into a structural design analysis [26]. Further work in this direction is required, particularly with respect to the identification of the physical processes corresponding to the parameters obtained, and this is currently under way.

\section{CONCLUSIONS}

A series of resins and their composites has been aged in water to simulate marine conditions. With respect to the initial objectives of the study the following conclusions may be drawn:

- Distilled water aging differs significantly from sea water aging in terms of 
weight gain but in terms of the shear property changes measured here the former is only slightly more severe. The composite weight gains show several anomalies, both with respect to resin behaviour and when different aging media and temperatures are considered.

- While permanent damage is induced in the polyester composites after 18 months, the epoxy and vinyl ester shear properties are much less affected by aging, and property losses for these two materials are largely recovered after drying.

- A simplified two parameter damage mechanics model has been applied to characterize the stress-strain behaviour based on load-unload cycles. Such models have rarely been applied to this type of marine composite previously, much less to follow aging effects. The results obtained here suggest that such an approach provides useful information which complements the more traditional modulus and strength parameters used to characterize material behaviour and evaluate aging effects. This offers the potential for a more complete characterization of mechanical behaviour and subsequent integration into complex structural models.

\section{APPENDIX}

\section{Example of the Determination of Damage Mechanics Parameters}

Three kinds of shear properties have to be determined: elastic, damage and inelastic. Damage variables and inelastic strains are measured by means of loading-unloading cycles during a tensile test on a [ \pm 45$]$ lay-up specimen (Figure 15). The shear stress-strain curve $\left(\sigma_{12}, \varepsilon_{12}\right)$ is obtained from the linear relation between the longitudinal strain $\varepsilon_{L}$, the transverse strain $\varepsilon_{T}$ and the macroscopic stress $\sigma_{L}$ [Equation (10)].

$$
\sigma_{12}=\frac{\sigma_{L}}{2} \quad \varepsilon_{12}=\frac{\varepsilon_{L}-\varepsilon_{T}}{2} \quad \sigma_{12}=2 G_{12} \cdot \varepsilon_{12}
$$

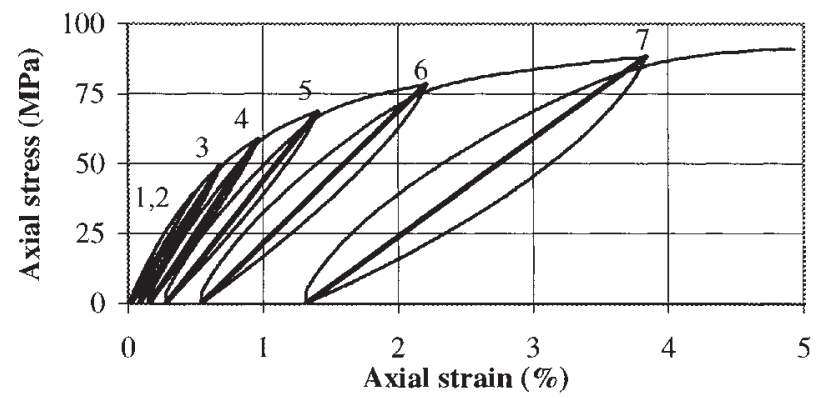

Figure 15. Load-unload cycles, unaged glass/epoxy (the first two cycles are not shown). 
The elastic shear modulus is measured as a linear regression of the curve between the strains 0 and $0.1 \%$. Then, for each load cycle $i$, a set of the following quantities is calculated:

- the damage variable $d_{i}$ characterized on the stress-strain curve by the reduction of the elastic modulus

$$
d_{i}=1-\frac{G_{12}^{i}}{G_{12}^{0}}
$$

- the thermodynamic force $Y_{d i}$ evaluated with Equation (12) and the maximum value of the shear stress $\sigma_{i}$

$$
Y_{d i}=\frac{\sigma_{12}^{i 2}}{2 G_{12}^{0}\left(1-d_{i}\right)^{2}}
$$

- the permanent strain $\varepsilon_{12}^{i p}$ measured at the zero stress points after unloading

- The threshold value $R_{i}$ is obtained from the measurement of the shear stress as

$$
R_{i}=\frac{\sigma_{12}^{i}}{\left(1-d_{i}\right)}
$$

All these values for the example above in Figure 15 are shown in Table 5. The damage master curve $d=f\left(Y_{d}\right)$ is shown in Figure 16. Results are shown both from seven cycles on a single specimen and from two cycles on each of the three other unaged specimens.

The damage coefficient $\lambda$ and the threshold damage value $Y_{0}$ are calculated by a least square fit of the model [Equation (5)] to the experimental points. The higher the value of $\lambda$ the faster damage increases with loading. The results are in Table 6.

The construction of the plasticity master curve expressed by Equation (9) re-

Table 5. Parameters for unaged glass/epoxy.

\begin{tabular}{cccccccc}
\hline Cycle & $\begin{array}{c}\boldsymbol{\sigma}_{\boldsymbol{i}}, \\
\mathbf{M P a}\end{array}$ & $\varepsilon_{\mathbf{1 2}}^{i \boldsymbol{p}} \times \mathbf{1 0}^{-\mathbf{4}}$ & $\boldsymbol{d}_{\boldsymbol{i}}$ & $\begin{array}{c}\boldsymbol{Y}_{\boldsymbol{d i}}, \\
\mathbf{M P a}\end{array}$ & $\mathbf{2 ( 1 - \boldsymbol { d } _ { \boldsymbol { i } } )}$ & $\boldsymbol{p}$ & $\begin{array}{c}\boldsymbol{R}(\boldsymbol{p}), \\
\mathbf{M P a}\end{array}$ \\
\hline 1 & 20 & 1 & 0.02 & 0.14 & 1.97 & 0.0001 & 5 \\
2 & 39 & 4 & 0.18 & 0.34 & 1.65 & 0.0002 & 12 \\
3 & 49 & 8 & 0.24 & 0.45 & 1.53 & 0.0007 & 26 \\
4 & 59 & 15 & 0.33 & 0.62 & 1.34 & 0.0013 & 37 \\
5 & 69 & 28 & 0.45 & 0.89 & 1.09 & 0.0021 & 54 \\
6 & 78 & 54 & 0.60 & 1.37 & 0.81 & 0.0033 & 85 \\
7 & 88 & 131 & 0.73 & 2.34 & 0.53 & 0.0051 & 147 \\
\hline
\end{tabular}




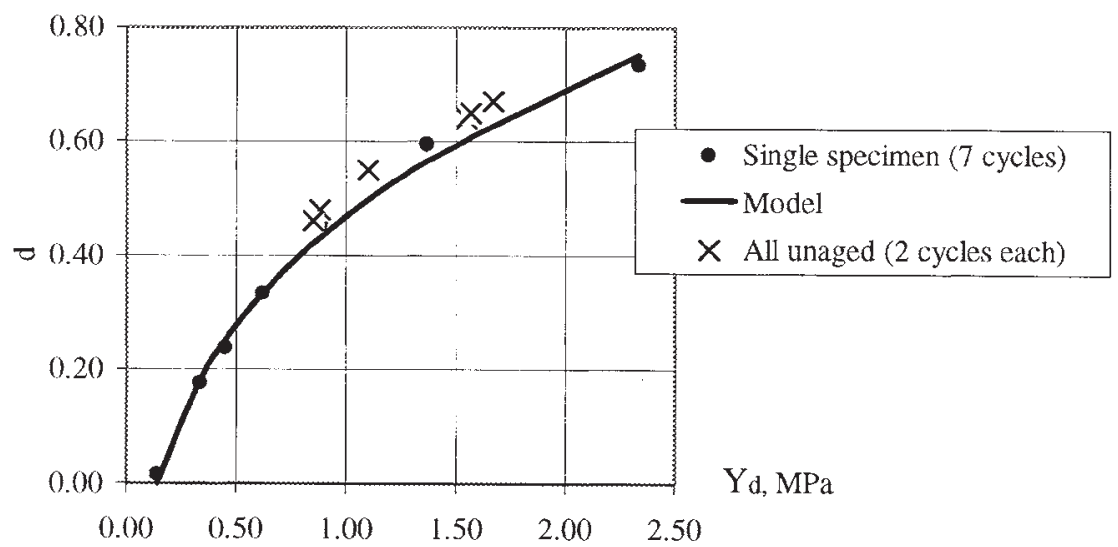

Figure 16. Damage master curve for unaged glass/epoxy.

quires cumulative integration of the $R$ versus $\varepsilon_{12}^{p}$ plot [25]. Indeed, plastic strains depend on the history of loading and take the corresponding values of damage into account. Then:

$$
p_{i}=\int_{0}^{\varepsilon_{12}^{p i}} 2(1-d) d \varepsilon_{12}^{p}
$$

The expressions for the plastic threshold and the cumulated plastic $p$ strain have been established in Equation (8). The variable $p$ is obtained from Equation (7) and evaluated by integrating the area shown in Figure 17. The values of $p$ are calculated and plotted on the plasticity master curve (Figure 18).

The square root model used here [Equation (9)] is the most widespread, but the choice of model remains controversial, as one must decide whether the low or the high values of plastic strains are to be well fitted. Indeed, the irreversible mechanisms responsible for inelastic strains might change between low and high values, particularly in a test on specimens with fibres oriented at $\pm 45^{\circ}$.

Here model 1 [Equation (9)] is fitted to the experimental values. This model has been chosen for all the tests in the present study of aging. This choice is convenient for the representation of high plastic strains. The linear model 2 seems to produce an improved fit, and indeed some applications of Damage Mechanics theory to

Table 6. Damage coefficients, unaged glass/epoxy.
$\lambda\left(\mathrm{MPa}^{(-1 / 4)}\right)$
1.16
$Y_{0}(\mathrm{MPa})$
0.14 


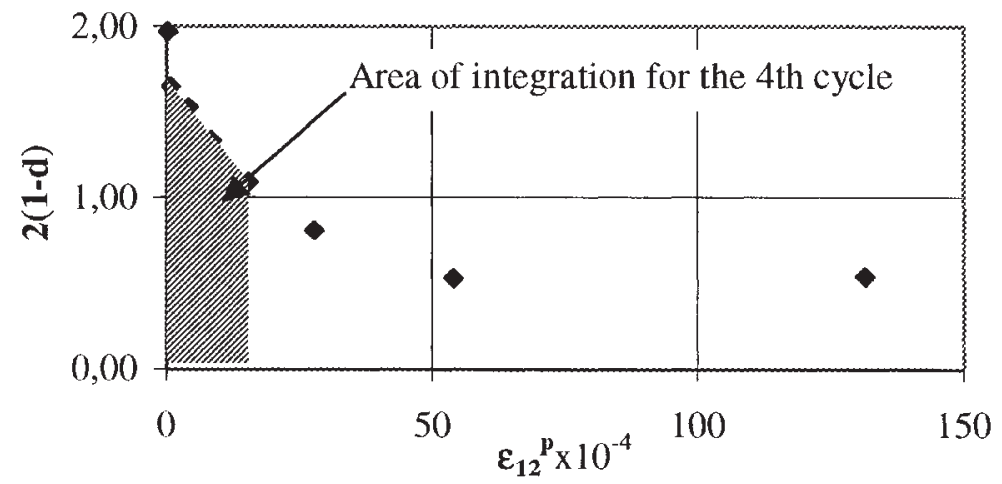

Figure 17. Integration for the calculation of the plastic strain $\mathrm{p}$.

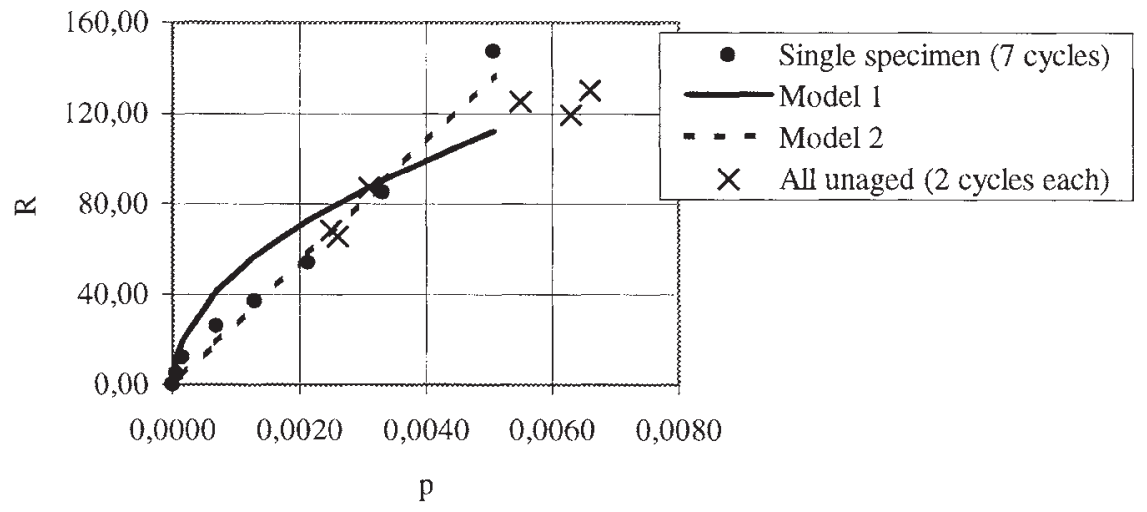

Figure 18. Plasticity master curve. 


\section{$\beta(\mathrm{MPa}) \quad 1569$}

woven composites use this shape of plastic master curve [27], but it was found to be less consistent with the high plastic strain cycle values used in this work to characterise aging.

In both of these simplified models, the plastic properties are characterized by means of only one parameter, $\beta$. The lower the value of $\beta$ the faster plastic strains increase with loading. The value of $\beta$ is taken from the "model 1" fit (Table 7).

\section{REFERENCES}

1. Smith CS, "Design of marine structures in composite materials," Elsevier Applied Science, London, 1990.

2. Davies P and Lemoine L (eds.), Proc. 3rd Int. Conf. on "Nautical Construction with Composite Materials," Paris 1992, IFREMER editions, Brest.

3. Graner WR, "Marine Applications, Handbook of Composites," ed. G. Lubin, van Nostrand, 1982, p. 699.

4. Gibson AG, "Composites structures in offshhore applications," chapter 11 in Composite Materials in Maritime Structures, eds. Shenoi RA and Wellicome JF, Cambridge Ocean Technology Series, 1993.

5. Chauchot $P$ and Guillermin $O$, "On the use of composite materials for $6000 \mathrm{~m}$ containers," Proc 8 th European SAMPE Conf., 1987, pp. 312-328.

6. Springer G.S (ed.), "Environmental effects on composite materials," Technomic, Lancaster, 1981.

7. Wolff EG, "Moisture effects on polymer matrix composites," SAMPE Jnl. 29, 3, May/June 1993, p. 11.

8. Lagrange A, Melennec C and Jacquemet R, "Influence of various stress conditions on the moisture diffusion of composites in distilled water and natural sea water," in Durability of Polymer Based Composites Systems for Structural Applications, eds. Cardon AH, Verchery G, Elsevier, 1991, p. 385.

9. Grant TS, "Seawater degradation of polymeric composites," MSc thesis, Texas A\&M University, May 1991.

10. Apicella A, Migliaresi C, Nicolais L, Iaccarino L, and Roccotelli S, "The water ageing of unsaturated polyester-based composites," Composites 14, 4, October 1983, p. 387.

11. Gutierrez J, LeLay F and Hoarau P, "A study of the aging of glass fibre-resin composites in a marine environment," in Reference [2], p. 338.

12. Choqueuse D, Davies P, Mazéas F and Baizeau R, "Aging of composites in water," ASTM STP 1302, eds. Gates TS, Zureick A-H, 1997, p. 73.

13. Weitsman Y. "Effect of fluids on polymeric composites—A review," Report MAES 95CM, July 1995, Univ. of Tennessee.

14. Pritchard G and Speake SD, "The use of water absorption kinetic data to predict laminate property changes," Composites 18, 3, July 1987, p. 227.

15. Kenig S, Moshonov A, Shucrun A and Marom G, "Environmental effects on shear delamination of fabric reinforced epoxy composites," Int. J. Adhesion and Adhesives, 9, 1, Jan. 1989, p. 38.

16. Davies P, Pomiès F and Carlsson LA, "Influence of water and accelerated aging on the shear fracture properties of glass/epoxy composites," Appl. Comp. Materials., 3, 1996, pp. 71-87. 
17. Ladevèze P, "On a damage mechanics approach," in Mechanics and Mechanisms of Damage in Composites and Multimaterials, ESIS 11, ed. D. Baptiste, MEP, London, 1991, p. 119.

18. Rosen BW, "A simple procedure for experimental determination of the longitudinal shear modulus of unidirectional composites," J. Comp. Mats., 6, October 1972, p. 552.

19. Chatterjee S, Adams D and Oplinger DW, "Test methods for composites, a status report. Volume III: Shear test methods," U.S. Department of Transportation Report DOT/FAA/CT-93/17, June 1993.

20. Compston P, Jar P-Y B and Davies P, "Matrix effect on the static and dynamic interlaminar fracture toughness of glass-fibre marine composites," Composites Part B, 29B, 1998 p. 505.

21. Ladevèze P and Le Dantec E, "Damage modeling of the elementary ply for laminated composites," Composite Science and Technology, 43, 1992, pp. 257-267.

22. Herakovich CT, "Mechanics of fibrous composites," John Wiley and Sons, Inc., 1998.

23. Ladevèze P, "Inelastic strain and damage modeling," Damage Mechanics of Composite Materials, ed. R. Talreja, Elsevier Science, 1993.

24. Casari P, De Roeck Y-H and Allix O, "Damage behaviour of glass reinforced marine composites materials," ECCM-7, vol. 2, pp. 247-252, London, 1996, Ed. Woodhead Publishing Limited.

25. Casari $\mathrm{P}$, Ladevèze $\mathrm{P}$, and Chou $\mathrm{T}-\mathrm{W}$, "Damage modeling and characterization of a three-dimensional woven composite," Proceedings ICCM-12, Paris 1999, paper 717.

26. Ladevèze $\mathrm{P}$, "A damage computational method for composite structures," Computer and Structure, 44, 1992, pp. 79-87.

27. Charles J-P, Hochard C and Aubourg P-A, Proc. ICCM-12, Paris 1999, paper 746. 